\title{
Trends and area variations in Potentially Preventable Admissions for COPD in Spain (2002-2013): a significant decline and convergence between areas
}

Julián Librero ${ }^{1,2^{*}}$, Berta Ibañez-Beroiz $2^{2,3}$, Salvador Peiró ${ }^{1,2}$ (1) M. Ridao-López ${ }^{1,2,4}$, Clara L. Rodríguez-Bernal ${ }^{1,2}$, Francisco J. Gómez-Romero ${ }^{2,4}$, Enrique Bernal-Delgado ${ }^{2,4}$ and the Spanish Atlas of Medical Practice Variation Research Group

\begin{abstract}
Background: Potentially Preventable Hospitalizations (PPH) are hospital admissions for conditions which are preventable with timely and appropriate outpatient care being Chronic Obstructive Pulmonary Disease (COPD) admissions one of the most relevant PPH. We estimate the population age-sex standardized relative risk of admission for COPD-PPH by year and area of residence in the Spanish National Health System (sNHS) during the period 2002-2013.

Methods: The study was conducted in the 203 Hospital Service Areas of the sNHS, using the 2002 to 2013 hospital admissions for a COPD-PPH condition of patients aged 20 and over. We use conventional small area variation statistics and a Bayesian hierarchical approach to model the different risk structures of dependence in both space and time.
\end{abstract}

Results: COPD-PPH admissions declined from 24.5 to 15.5 per 10,000 persons-year (Men: from 40.6 to 25.1; Women: from 9.1 to 6.4). The relative risk declined from 1.19 (19\% above 2002-2013 average) in 2002 to 0.77 (30\% below average) in 2013. Both the starting point and the slope were different for the different regions. Variation among admission rates between extreme areas dropped from 6.7 times higher in 2002 to 4.6 times higher in 2013.

Conclusions: COPD-PPH conditions in Spain have undergone a strong decline and a reduction in geographical variation in the last 12 years, suggesting a general improvement in health policies and health care over time. Variability among areas still remains, with a substantial room for improvement.

Keywords: Potentially preventable hospitalizations, Chronic obstructive pulmonary disease, Small area variation analysis, Hospitalization

\footnotetext{
* Correspondence: librero_jul@gva.es

Prior abstract presentation: Partial results were presented at the VII National Meeting of Care for Chronic Patients organized by the Spanish Society of Internal Medicine and the Spanish Society of Family Medicine, Valladolid, Spain, March 5-7, 2015; and in the XVth Spanish Biometric Conference and Vth Ibero-American Biometric Meeting Conference (CEBEIB2015), Bilbao, Spain, September 22, 2015.

${ }^{1}$ Centro Superior de Investigación en Salud Pública (CSISP-FISABIO),

Catalunya Av. 21, 46020 Valencia, Spain

${ }^{2}$ Red de Investigación en Servicios de Salud en Enfermedades Crónicas

(REDISSEC), Valencia, Spain

Full list of author information is available at the end of the article
} 


\section{Background}

Potentially Preventable Hospitalizations (PPH) are hospital admissions for certain acute illnesses or worsening chronic conditions that may be theoretically preventable with timely and appropriate outpatient care [1, 2]. PPH rely on hospital discharge data but are intended as indirect indicators of accessibility to high-quality outpatient care [3-5]. Despite a recent decline in smoking habits and age-adjusted mortality rates [6, 7], Chronic Obstructive Pulmonary Disease (COPD) remains a leading cause of morbidity and mortality [8]. Because appropriate, continuous and well-organized outpatient care in COPD patients could improve symptoms, reduce severity and avoid hospitalization, most COPD hospital admissions are incorporated into the set of $\mathrm{PPH}$ indicators [2], and in fact COPD hospitalizations are one of the most relevant $\mathrm{PPH}$, providing between a third and a half of all cases of chronic PPHs in Spain [3, 4] and Europe [5].

Access to care and quality varies between areas and regions $[9,10]$. Most PPH studies in COPD use small area variation analysis, disease mapping or other methods to show geographical variations in hospital admissions at a particular time, and/or to relate this variation to demographic or social factors, the supply of health services, physician practice styles or risk exposure [11-15]. But accessibility to high-quality healthcare can also change over time, and with a variable rhythm between areas served by different healthcare organizations. However, time trends for COPD-PPH have barely been studied and, to our knowledge, no study has simultaneously analyzed spatial and temporal variability in COPD-PPH.
Understanding geographical variations and trends in COPD-PPH is important for assessing accessibility to appropriate care and also for formulating public health initiatives to reduce the burden of this disease. The objectives of this study were to estimate the population age and sex standardized relative risk (RR) of hospitalization for COPD-PPH by year and area of residence in the Spanish National Health System (sNHS) during the period 2002-2013, and to describe its average trends and the evolution of its spatial heterogeneity.

\section{Methods}

Design

Population based spatio-temporal study using "hospital service areas" (HSAs) as a unit of analysis.

\section{Setting}

The study was conducted in the sNHS, a decentralized structure of 17 regional National Health Services (NHS) administered by the 17 Autonomous Governments of the Spanish regions [16, 17]. During the study period healthcare coverage was almost universal. Regional NHSs operate an extensive network of hospitals (about $75 \%$ of acute hospital beds in Spain), and specialized outpatient and primary healthcare centres. Healthcare in this network is free of charge (except for co-payment for outpatient prescriptions) and supported by Regional Government budgets. In 2013 the 17 sNHS regions were organized into 203 HSAs, geographical territories -most of them between 150,000 and 250,000 people- served by one NHS hospital that provides specialized inpatient and outpatient care to the residents in its area. Primary care is

Table 1 Number of COPD-PPH admissions and standardized rates in people aged 20 and over in the Spanish National Health System (rates by 10,000 person-year; 2002-2013)

\begin{tabular}{|c|c|c|c|c|c|c|c|c|c|c|c|c|}
\hline Year & 2002 & 2003 & 2004 & 2005 & 2006 & 2007 & 2008 & 2009 & 2010 & 2011 & 2012 & 2013 \\
\hline Population aged $20+$ (n, millions) & 33.34 & 34.13 & 34.66 & 35.45 & 36.09 & 36.53 & 37.15 & 37.49 & 37.67 & 37.79 & 37.86 & 37.75 \\
\hline Population aged 65+ (\%) & 21.60 & 21.41 & 21.17 & 20.79 & 20.80 & 20.69 & 20.61 & 20.84 & 21.01 & 21.37 & 21.67 & 22.03 \\
\hline Hospitalizations (n) & 75036 & 77893 & 72276 & 80027 & 68623 & 77195 & 72647 & 70952 & 64583 & 65315 & 64932 & 61348 \\
\hline Men & 60485 & 63180 & 58642 & 65176 & 55959 & 62813 & 58901 & 57384 & 51981 & 52364 & 51592 & 48193 \\
\hline Women & 14551 & 14713 & 13634 & 14851 & 12664 & 14382 & 13746 & 13568 & 12602 & 12951 & 13340 & 13155 \\
\hline$\%$ Women & 19.37 & 18.91 & 18.87 & 18.58 & 18.48 & 18.68 & 18.95 & 19.13 & 19.53 & 19.86 & 20.57 & 21.49 \\
\hline Patients' age (mean, years) & 73.17 & 73.32 & 73.58 & 73.94 & 73.86 & 74.16 & 74.25 & 74.05 & 73.76 & 74.26 & 74.60 & 74.21 \\
\hline Men & 72.84 & 73.00 & 73.34 & 73.76 & 73.84 & 74.19 & 74.27 & 74.24 & 73.95 & 74.51 & 74.94 & 74.68 \\
\hline Women & 74.53 & 74.66 & 74.61 & 74.76 & 73.94 & 74.03 & 74.16 & 73.22 & 72.99 & 73.26 & 73.28 & 72.50 \\
\hline Standardized Rate 10,000 p-y & 24.46 & 24.70 & 22.13 & 24.05 & 20.19 & 22.24 & 20.45 & 19.42 & 17.26 & 17.03 & 16.64 & 15.53 \\
\hline Men & 40.62 & 41.03 & 36.89 & 40.21 & 33.97 & 37.11 & 34.20 & 32.29 & 28.60 & 28.07 & 27.19 & 25.11 \\
\hline Women & 9.07 & 9.13 & 8.07 & 8.65 & 7.05 & 8.06 & 7.35 & 7.16 & 6.45 & 6.50 & 6.59 & 6.40 \\
\hline Relative Risk of admission & 1.19 & 1.22 & 1.11 & 1.19 & 1.02 & 1.11 & 1.03 & 0.98 & 0.86 & 0.85 & 0.83 & 0.77 \\
\hline
\end{tabular}

Relative Risk in relation to the whole 2002-2013 hospitalization rate 
organized into local zones -most of them between 5000 and 25,000 people- associated to their respective HSA. Due to these organizational characteristics (geographical planning, minimal accessibility barriers, and the practical absence of economic incentives to providers), patients receive most of their inpatient and outpatient care in the HSA where they live.

\section{Sources of data}

The Minimum Basic Hospital Discharge Dataset of the Regional NHSs from 2002 to 2013 was used to search for COPD-PPH admissions. This database provides clinical and sociodemographic information on all hospital discharges in the sNHS, including diagnoses and procedures coded according to the International Classification of Diseases 9th revision Clinical Modification (ICD9CM). The population denominators for each year were obtained from the annual census of the Spanish National Institute of Statistics.

\section{Population}

All 2002 to 2013 hospital admissions of patients aged 20 and over for a COPD-PPH condition defined as following the Spanish validation $[18,19]$ of the US Agency for Healthcare Research and Quality Prevention Quality Indicators [2]. This Spanish version is similar to the US version (see Additional file 1, e-Appendix 1 for differences between versions) but with some ICD9CM codes adapted to the most common codification patterns in the sNHS and have been used in previous studies [5, 20, 21].

\section{Main endpoint}

Age-sex standardized rates of COPD-PPH by 10,000 persons-years (men, women and total) for each HSA.
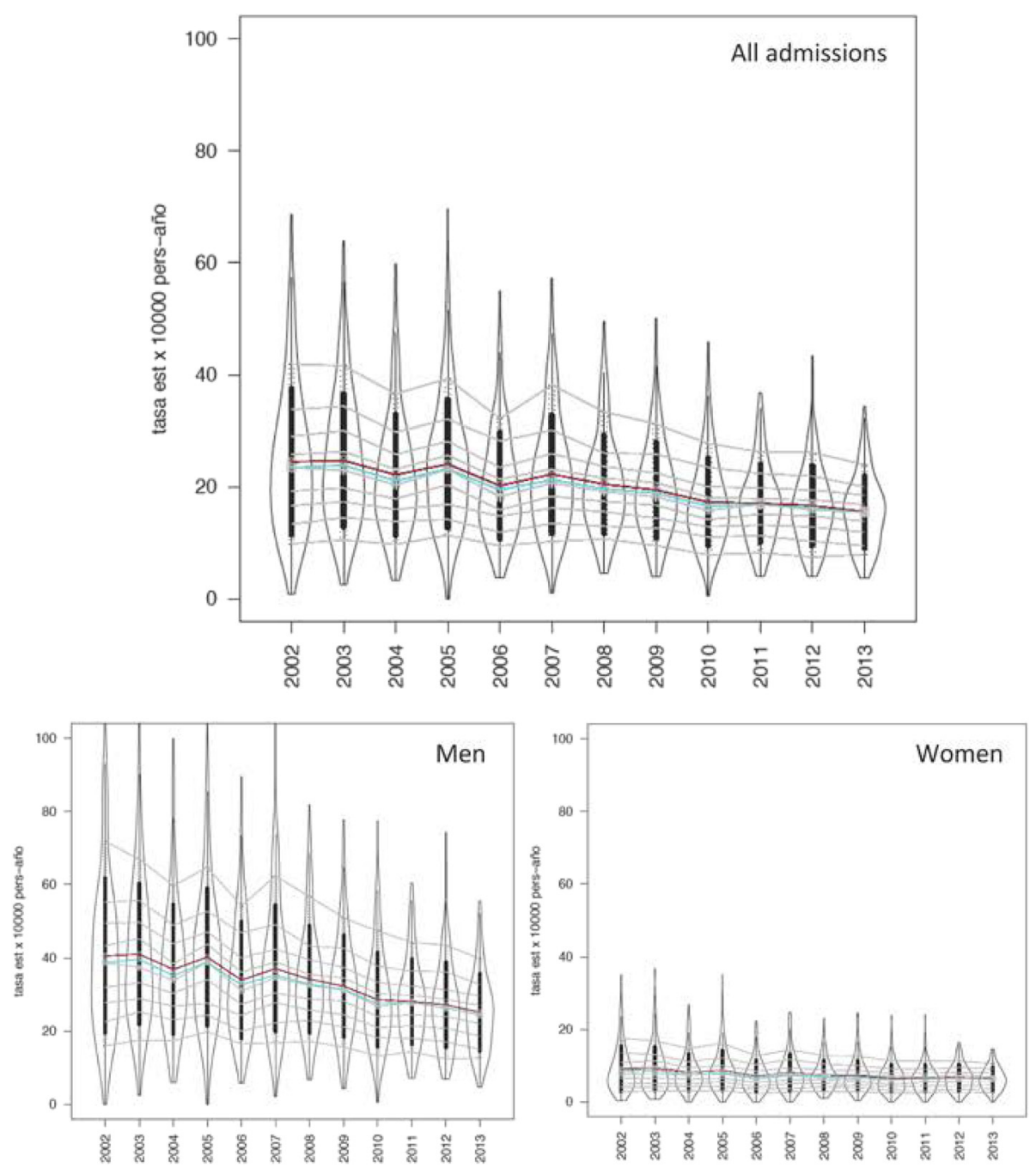

Fig. 1 Distribution of COPD-PPH standardized rates among Hospital Service Areas for the overall population, men and women (Spanish NHS, 2002-2013). Foot: COPD-PPH: Chronic Obstructive Pulmonary Disease for Potentially Preventable Hospitalizations; NHS: National Health System. Gray lines represent deciles and coloured lines the median (red) and the mean (blue) 


\section{Analysis}

First, all 2002 to 2013 COPD-PPH admissions of patients aged 20 and over were selected, linked to their HSA of residence and aggregated into 14 age-sex groups (20-44, 45-64, 65-69, 70-74, 75-79, 80-84, 85 and over, for both genders). Age-sex standardized rates were calculated by applying age-sex specific weights representing the importance of each group in the overall population of each area. Variation among HSAs was assessed through the ratio between the $95^{\text {th }}$ and $5^{\text {th }}$ percentiles, the ratio between the $75^{\text {th }}$ and $25^{\text {th }}$ percentiles and the coefficient of variation of the COPD-PPH standardized rates per 10,000 persons-year. Under the hypothesis that risk remains constant in space and time, the expected number of cases per HSA was estimated by applying the rate for all areas over the 12 years to the population at risk in each HSA in the respective year. Standardized Hospitalization Ratios (SHRs) were estimated using the ratio of observed-toexpected cases, interpretable as the maximum estimate of the risk ratio of admissions for a COPD-PPH in that area in that period.

We use a Bayesian hierarchical approach to model the different risk structures of dependence in both space and time. In the first level of this hierarchical modelization, we assume that, conditional on the underlying relative risk, the number of counts $y_{j t}$ in the $j$ th area at the $t$ th time period follows a Poisson distribution with mean $u_{j t}=e_{j t} r_{j t}$, where $e_{j t}$ is the number of expected counts and $r_{j t}$ the unknown relative risk. In the second level, the $\log \left(r_{i j}\right)$ was expressed as the sum of the components representing the individual and independent contributions to the risk in a specific HSA and period $\left[\log \left(r_{i j}\right)=\right.$ intercept $\left.+S_{i}+T_{j}+S T_{i j}\right]$, where the intercept term gives the initial level of risk that is shared by all regions and periods. The main effects $S_{i}$ and $T_{j}$ represent the additional risk of living in region $i$ and period $j$ and the second order interaction term $S T_{i j}$ represent the risk contribution due to a combination of the effects that cannot be explained additively by the main effects. In the third level, a hyperparameter-prior distribution was assumed where the spatial effect was modelled following a convolution CAR prior [22]. The temporal main effect was a combination of a time-unstructured (exchangeable) and a time structured effects (first order random walk), and the interaction term can be thought of as the independent unobserved covariates for each combination of region and period $(i, j)$, thus without any structure (Type I in the Knorr-Held classification) [23] .

As a summary measure of the uncertainty surrounding the estimate of relative risk, the posterior expected excedence probability $(\operatorname{Pr}(R R>1))$ is represented [24]. Integrated nested Laplace approximations (INLAs) were used as a tool for Bayesian inference [25]. For this

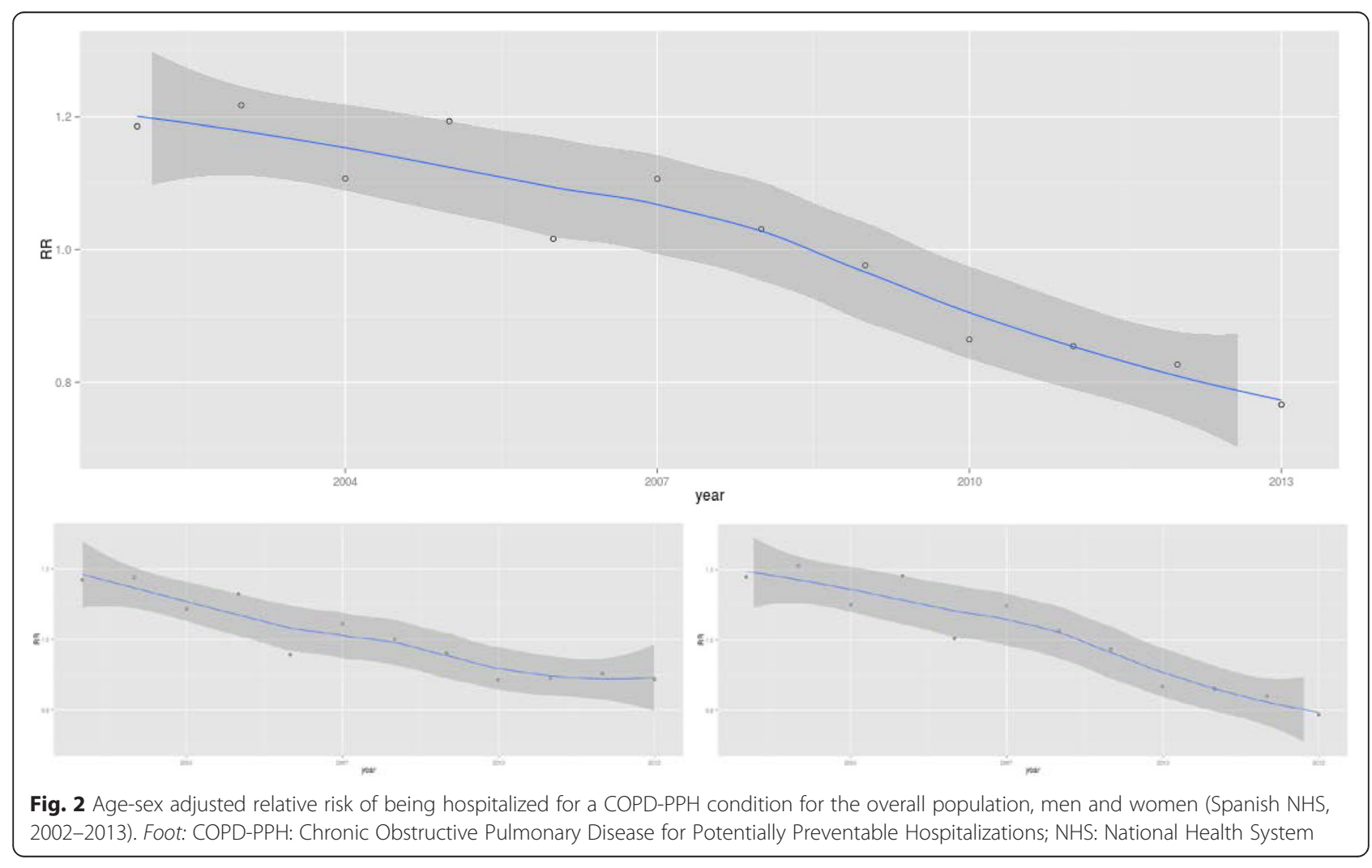


purpose, we used R-INLA with the option of simplified Laplace estimation of the parameters, a package available in the R environment [26].

\section{Results}

COPD-PPH admissions in people aged 20 and over declined from 75,036 to 61,348 during the study period (Table 1, Fig. 1), more markedly in men (from 60,485 to 48,$193 ;-20.32 \%$ ) than women (from 14,551 to 13,155 ; $-9.59 \%)$. Women's hospitalizations increased from 19.4 to $21.5 \%(+10.9 \%)$ and the patients' mean age increased from 73,2 to 74,2 years old at the expense of men (from 72,8 to 74,7 years old vs. a decrease from 74,5 to 72,5 in women). Because the population over 20 rose in this period from 33.3 million in 2002 to nearly 37.7 million in 2009, COPD-PPH age-sex standardized rates declined more sharply: from 24.5 to 15.5 per 10,000 py $(-36.7 \%$; from 40.6 to $25.1,-38.2 \%$ in men, and from 9.1 to 6,4 , $-29.7 \%$ in women).

Figure 2 displays the age-sex adjusted relative risk of being hospitalized for a COPD-PPH condition throughout the study period compared with the average rate over the 12 years studied. This RR, clearly descending throughout almost the whole period, ranged from 1.19 (19 \% above the 2002-2013 average) in 2002 to 0.77 (30 \% below average) in 2013, but for women the downward trend flattens out in the final years. Both the starting point and the slope were different for the different regions (Fig. 3), with a strong reduction in variability during the study period. For specific trends for Autonomous Regions, gender and age groups see Additional file 2, e-Appendix 2.

Regarding variation among HSAs (Table 2), the standardized rate for the HSA in the P95 was 6.7 times

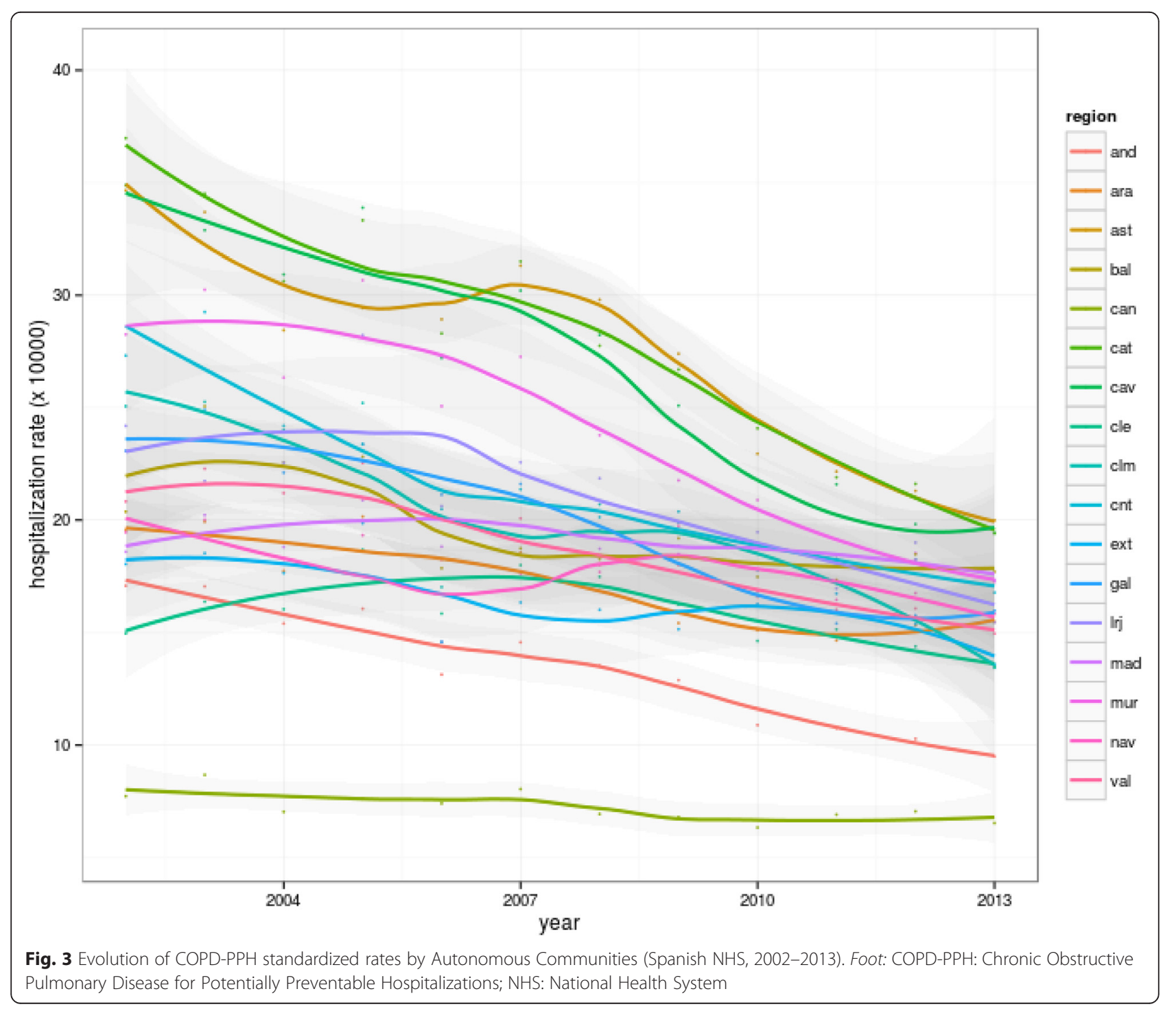


Table 2 Variation in standardized rates of COPD-PPH admissions in people aged 20 and over in the Spanish National Health System (2002-2013)

\begin{tabular}{|c|c|c|c|c|c|c|c|c|c|c|c|c|}
\hline Year & 2002 & 2003 & 2004 & 2005 & 2006 & 2007 & 2008 & 2009 & 2010 & 2011 & 2012 & 2013 \\
\hline \multicolumn{13}{|l|}{ All } \\
\hline Rate $10000 \mathrm{p}-\mathrm{y}, \mathrm{HSA}$ in the $10^{\text {th }}$ Percentile & 9.82 & 10.47 & 9.70 & 11.36 & 9.45 & 10.23 & 10.69 & 9.49 & 7.84 & 8.21 & 7.44 & 7.89 \\
\hline Rate $10000 p-y, H S A$ in the $90^{\text {th }}$ Percentile & 41.94 & 41.62 & 36.59 & 39.33 & 32.16 & 38.16 & 33.37 & 31.19 & 27.74 & 26.24 & 26.15 & 23.95 \\
\hline Ratio between $95^{\text {th }} / 5^{\text {th }}$ Percentiles & 6.86 & 4.97 & 5.57 & 5.07 & 4.66 & 4.75 & 4.52 & 5.11 & 4.71 & 4.48 & 4.21 & 4.62 \\
\hline Ratio between $75^{\text {th }} / 25^{\text {th }}$ Percentiles & 2.11 & 2.00 & 1.89 & 1.93 & 1.85 & 1.91 & 1.69 & 1.79 & 1.82 & 1.74 & 1.77 & 1.79 \\
\hline Coefficient of Variation & 0.53 & 0.48 & 0.48 & 0.47 & 0.47 & 0.47 & 0.43 & 0.43 & 0.45 & 0.41 & 0.42 & 0.41 \\
\hline \multicolumn{13}{|l|}{ Men } \\
\hline Rate $10000 \mathrm{p}-\mathrm{y}, \mathrm{HSA}$ in the $10^{\text {th }}$ Percentile & 15.98 & 17.45 & 17.37 & 19.75 & 16.52 & 16.80 & 17.14 & 15.68 & 13.14 & 14.28 & 12.35 & 12.58 \\
\hline Rate $10000 \mathrm{p}-\mathrm{y}, \mathrm{HSA}$ in the $90^{\text {th }}$ Percentile & 71.83 & 62.93 & 59.70 & 64.68 & 54.16 & 62.33 & 56.67 & 50.93 & 47.41 & 44.30 & 43.55 & 39.84 \\
\hline Ratio between $95^{\text {th }} / 5^{\text {th }}$ Percentiles & 6.61 & 4.85 & 5.38 & 4.61 & 4.46 & 5.00 & 4.33 & 5.36 & 4.74 & 4.60 & 4.48 & 4.81 \\
\hline Ratio between $75^{\text {th }} / 25^{\text {th }}$ Percentiles & 2.07 & 1.90 & 1.81 & 1.90 & 1.84 & 1.74 & 1.73 & 1.72 & 1.76 & 1.72 & 1.72 & 1.81 \\
\hline Coefficient of Variation & 0.52 & 0.47 & 0.48 & 0.47 & 0.47 & 0.47 & 0.43 & 0.43 & 0.45 & 0.41 & 0.43 & 0.42 \\
\hline \multicolumn{13}{|l|}{ Women } \\
\hline Rate $10000 \mathrm{p}-\mathrm{y}, \mathrm{HSA}$ in the $10^{\text {th }}$ Percentile & 2.84 & 2.98 & 3.06 & 3.10 & 2.26 & 2.76 & 2.86 & 2.84 & 2.37 & 2.50 & 2.53 & 2.59 \\
\hline Rate $10000 \mathrm{p}-\mathrm{y}, \mathrm{HSA}$ in the $90^{\text {th }}$ Percentile & 17.56 & 16.82 & 14.74 & 16.19 & 12.68 & 14.37 & 12.78 & 12.67 & 11.24 & 11.20 & 11.26 & 10.45 \\
\hline Ratio between $95^{\text {th }} / 5^{\text {th }}$ Percentiles & 10.75 & 9.23 & 9.57 & 7.74 & 9.34 & 9.73 & 6.02 & 7.53 & 7.81 & 6.90 & 7.16 & 6.11 \\
\hline Ratio between $75^{\text {th }} / 25^{\text {th }}$ Percentiles & 2.65 & 2.75 & 2.27 & 2.13 & 2.39 & 2.43 & 2.02 & 2.13 & 2.20 & 2.17 & 2.19 & 2.04 \\
\hline Coefficient of Variation & 0.69 & 0.66 & 0.62 & 0.63 & 0.62 & 0.63 & 0.54 & 0.58 & 0.58 & 0.55 & 0.53 & 0.49 \\
\hline
\end{tabular}

COPD-PPH Chronic Obstructive Pulmonary Disease admissions for Potentially Preventable Hospitalizations, HSA Health Service Areas, $p$-y persons-years

higher than the HSA in the P5 in 2002, while in 2013 this difference was reduced to 4.6 times higher. The ratio between HSAs in the P75 and P25 and the coefficient of variation confirms the variability in descent among HSAs. Violin graphs (Fig. 1) also visually show this double phenomenon of both strong decline and convergence in admission rates among HSAs.

Figure 4 displays the spatial patterns in standardized rates of COPD-PPH for the entire, male and female population. The left-hand maps show the COPD-PPH admission spatial risk associated to each HAS to be constant along the period. The right-hand map shows the posterior probability that this spatial risk will be higher than 1 (probabilities above 0.8 indicate high-risk HSAs), which seems to concentrate on the Northern coast, the Mediterranean coast and the central eastern area of Spain. See Additional file 3, e-Appendix 3 for the spatio-temporal evolution of COPD-PPH risks for each HSA.

\section{Discussion}

Our study primarily shows a large decline in the rate of admissions for COPD-PPH during the study period. This descending trend is consistent with other work in Spain restricted to hospitalization for COPD exacerbations during the period 2006-2010 [27], but studies in the USA (2001-2012) do not show changes in COPD admission or emergency room visits [28] and in other countries like France (1998-2007) rates have even increased [29]. Other studies in Brazil (1998-2008) [30], Finland (1998-2007) [31], and Australia (1993-2003) [32] show declining hospitalization rates, but sometimes only for men and less pronounced than those found in this study.

Possible causes of this sharp decline are probably diverse and include changes in the therapeutical management of COPD (increases in the utilization of inhaled long-acting beta-agonists, long-acting muscarinic antagonists, and inhaled corticosteroids), improvements in influenza vaccination coverage for high-risk patients, and organizational changes in the hospital accident and emergency departments reducing the volume of emergency hospital admissions for chronic exacerbations (introduction of observation units and higher coordination with Hospital at Home Units and Long Term Care Centres) [33]. Also, Primary Care Centres and Respiratory Medicine Departments in some HSAs have initiated disease management or case management programs for several chronic conditions, including COPD. [34] In this period Spain passed two smoking laws $(2006,2011)$ banning tobacco in workplaces and other public spaces. Furthermore, the severe economic crisis entailed a significant reduction in family income and a notable increase in excise duties on tobacco, resulting in a marked decline in cigarette consumption that perhaps affected patients with 


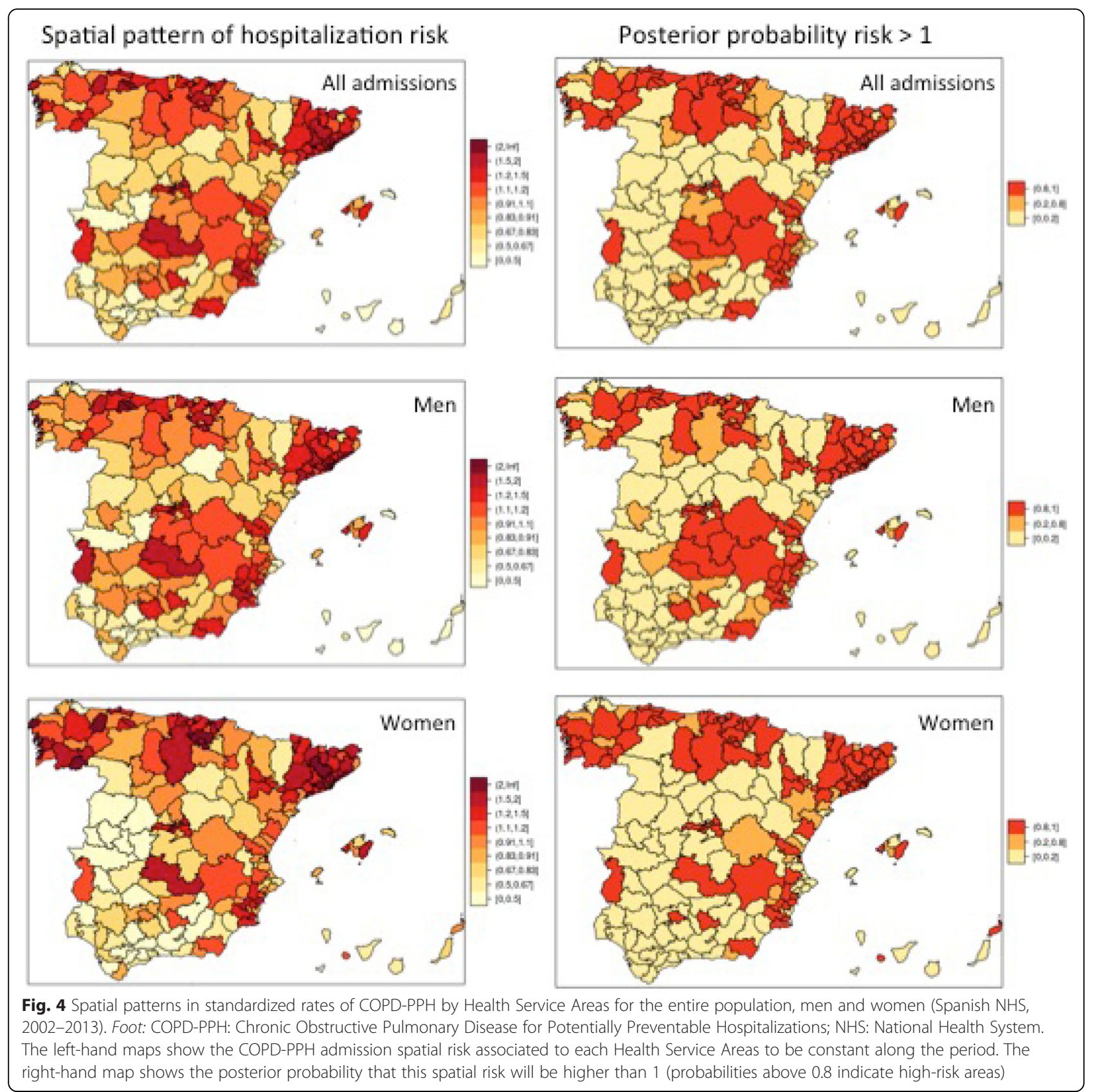

established COPD (on average, of lower socioeconomic strata) more heavily.

All these policies were active in Spain at the end of the study period but they started at different times, in some cases with a defined starting point, in other incrementally over time. Some policies (e.g., changes in admission criteria) would have a direct effect on admission rates, while other (e.g., anti-smoking laws) would have to be mediated through a reduction in the number of smokers or in the average tobacco consumption. We think that, on a downward trend derived from better management of COPD and a secular reduction in the tobacco consumption in adult males, changes in hospital admission criteria have been the main determinant of the reduction in COPD admission rates, while the impact of smoking laws could be gradually visible in the near future. But our data do not allow an estimation of the impact, if any, of each one of these cumulative number of different policies on COPDPPH rates.

Regarding geographical variation among HSAs, this also experienced a meaningful decrease by compression of the highest rates, but significant variability still remains. For 
example, with the 2013 rates in the HSA on the 90th percentile, the sNHS would have made around 90,000 COPD-PPH hospitalizations that year, compared to only 30,000 with the rates of the HSA on the 10th percentile. The regions with the highest rates of hospitalization (Catalonia, Asturias, Basque country) experienced the largest reductions. Interestingly, Andalusia, coming from one of the lowest rates of hospitalization, also experienced a significant reduction.

Among the study limitations, it is first worth noting that hospitalizations in private hospitals were not included, reducing overall hospitalization rates. The importance of this bias is difficult to quantify because most private Spanish hospitals specialize in elective surgery and deliveries than in chronic conditions, but according to the Spanish Hospital Morbidity Survey $21 \%$ of all hospitalizations for COPD in 2013 were carried out in private hospitals [35]. Both $\mathrm{PPH}$ and private provision of health care are associated with socio-economic level, and the private sector serves most of the employees of the Spanish Central Government (not employees of the regional Governments) that are concentrated in certain HSAs (provincial capitals and the Region of Madrid). Second, hospital admission rates, even standardized by age and sex, do not fully account for the differences in disease prevalence between areas or in the distribution of particularly vulnerable subpopulations [36, 37]. Third, the use of a Spanish PPH definition $[18,19]$ increases the internal study validity, but limits the contrast of our results with studies that used other definitions.

\section{Conclusions}

PPH have been adopted (and adapted) by different national and international organizations [38-40] and are currently a common and increasingly used instrument for the evaluation of health care [41, 42]. In Europe, where insurance tends to be universal and primary care is well developed, $\mathrm{PPH}$ are interpreted not only as a measure of outpatient care quality, but also of hospitals role in the control of chronic patients (discharging patients who are more or less stable, deciding which patients are admitted, etc.) and proper coordination between different levels of care [43].

Our study shows that COPD-PPH conditions in Spain have undergone a strong decline and a reduction in geographical variation by compression of the highest rates in the last 12 years, suggesting a general improvement in the management of COPD over time, specially in the HSAs with initial higher admission rates. Causes for this improvement and the relative value of each one will require further study, but may be of interest to the development of practical policies in Spain and other countries. Nonetheless, the remaining variability and the behaviour of some regions that have achieved substantial declines suggests that there is still considerable room for improvement.

\section{Additional files}

Additional file 1: CODES USED FOR IDENTIFICATION OF PPH-COPD ADMISSIONS. Data description: description of the criteria (including ICD-9-CM codes) for inclusion or exclusion of admissions as PPH-COPD. (PDF 58 kb)

Additional file 2: TEMPORAL TRENDS BY AGE-GROUP, SEX AND REGION Data description: e-Figure 1 and e-Figure 2 show the smoothed trends of PPH-CODP admissions stratified by four age groups and by autonomous regions, for men and women respectively. (PDF $9601 \mathrm{~kb}$ )

Additional file 3: SPATIO-TEMPORAL EVOLUTION OF THE COPD HOSPITALIZATION RISKS. Data description: e-Figure 1 displays the spatiotemporal evolution of COPD-PPH hospitalization relative risk for each Health Service area compared to the Spain average over the whole period, and e-Figure 2 the posterior probabilities that these relative risks were higher than 1. (PDF $6214 \mathrm{~kb}$ )

\section{Abbreviations}

COPD, chronic obstructive pulmonary disease; HSA, hospital service areas; ICD9CM, International Classification of Diseases 9th revision Clinical Modification; NHS, National Health Service; PPH, potentially preventable hospitalizations; RR, relative risk; sNHS, Spanish National Health System

\section{Collaborators}

The Spanish Atlas of Medical Practice Variation Research Group is formed by Andalusia: Díaz Martínez A (Hospital Virgen del Rocio de Sevilla), Goicoechea Salazar JA (Servicio Andaluz de Salud, Sevilla), Rivas Ruiz F, Jiménez Puente A (Hospital Costa del Sol, Marbella), Rodríguez del Águila MM (Hospital Virgen de las Nieves de Granada), Molina T, Baños E (Agencia de Evaluación de Tecnologías Sanitarias de Andalucía); Aragon: Angulo E, Bernal Delgado E, Comendeiro Maaløe M, Estupiñán Romero FR, García Armesto S, Launa R, Martínez Lizaga N, Ridao M, Seral Rodríguez M (Instituto Aragonés de Ciencias de la Salud-Instituto de Investigación Sanitaria Aragón), Abad Diez JM, Arribas Monzón F, Beltrán Peribáñez J, Pradas Arnal F (Departamento de Sanidad, Bienestar Social y Familia, Gobierno de Aragón); Asturias: Caicoya M, Suárez F (Consejería de Sanidad. Principado de Asturias); Canary Islands: Sánchez Janáriz H, Alonso Bilbao Jl, Fiuza Pérez D, (Servicio Canario de la Salud); Cantabria: Romero G (Consejería de Sanidad). Catalonia: Marinelli M (Agència de Qualitat i Avaluació Sanitàries de Catalunya, AQuAS), Oliva G (Departament de Salut), Ortún Rubio V (Universitat Pompeu Fabra, Barcelona); Salas T, Vela E (CatSalut- Servei Català de la Salut); Castilla-Leon: Sacristán Salgado A, García Crespo J (Dirección General de Desarrollo Sanitario), Melgosa Arcos A, Sangrador Arenas L (Dirección General de Planificación, Calidad, Ordenación y Formación); Castilla la Mancha: García Sánchez MA (Consejería de Sanidad y AS de Castilla-La Mancha); López Reneo R (Servicio Salud Castilla-La Mancha, SESCAM), Galicia: Atienza Merino G, Carballeira Roca C, Queiro T (Conselleria de Sanidade de la Xunta de Galicia), Castro Villares M (Servicio Galego de Saúde); Estremadura: Anes del Amo Y (Gobierno de Extremadura), Montes Salas G (Escuela de Estudios de Ciencias de la Salud); Balearic Islands: Castaño Riera EJ, Santos Terrón MJ, (Consejería de Salud); Zaforteza Dezcallar M (Servicio de Salud de las Illes Balears), Ferrer Riera J, Martín Martín MV (Hospital Son Llàtzer); Rioja: Cestafé A (Consejería de Salud); Madrid: Bienzobas López C, Gómez Lázaro R (Dirección General de Sistemas de Información Sanitaria, SERMAS); Murcia: Palomar Rodríguez J, Hernando Arizaleta L (Consejería de Sanidad de la Región de Murcia); Navarre: Álvarez Arruti N, Montes García Y, Rodrigo Rincón I (Departamento de Salud de Navarra- Osasunbidea), Ibáñez Beroiz B (Centro de Investigación Biomédica-Navarra); Basque Country: Aizpuru F, Latorre García PM, Latorre A, Pérez de Arriba J (Grupo de investigación del País Vasco, Osakidetza-SVS), Errezola M (Departamento de Sanidad del Gobierno Vasco), Millán E (Osakidetza-SVS); Valencia Community: Baixauli-Pérez C, Librero J, Peiró S, Rodríguez-Bernal CL, Sanfelix-Gimeno G (Fundación para el Fomento de la Investigación Sanitaria y Biomédica de la Comunidad Valenciana, FISABIO), Meneu R, Sotoca R (Fundación Instituto de Investigación en Servicios de Salud, flISS), Calabuig J (Conselleria de Sanitat, Generalitat Valenciana).

\section{Funding}

This study is part of the "Atlas of Medical Practice Variation in the Spanish National Health System" research project, funded by the Instituto de Salud 
Carlos III (Grants G03/202, PI05/2490, PI06/1673, PI10/00494 and PI14/ 00786, with cofinancing from the European Regional Development Fund), IBERCAJA, and the Fundación Instituto de Investigación en Servicios de Salud. This particular study is also funded by Collaboration Agreements in 2013 and 2014 between the Fundación para el Fomento de la Investigación Sanitaria y Biomédica (FISABIO, Valencia Ministry of Health) and Boehringer Ingelheim. CLRB and MRL were funded by grants RD12/0001/0005 and RD12/0001/0004 from the Instituto de Salud Carlos III, Spanish Ministry of Health, cofinanced by the European Regional Development Fund.

\section{Availability of data and material}

The datasets (dat.Rdata) and programmes (COPD_bmc.Rmd) analysed during the current study are available in the Spanish Atlas of Medical Practice Variation Research Group repository, [http://www.atlasvpm.org/documents/ 10157/87d16dac-02c3-47b4-9054-b05f78d4a0e7].

\section{Authors' contribution}

$J L$ and SP had full access to all the data in the study and take responsibility for the integrity of the data and the accuracy of the data analysis. The primary data acquisition is a collective task of the Spanish Atlas of Medical Practice Variation Research Group, with project coordination managed by the Aragon and Valencia research groups. JL, BIB and SP were responsible for the study concept, design and data acquisition from the Spanish Atlas Database. JL, MRL, FGR and CLRB carried out the data preparation and the statistical analysis and JL, BIB, SP and EBD drafted the manuscript. All authors participated in the analysis and interpretation of data, critical revision of the manuscript for important intellectual content, all approved the final version submitted for publication and agree to be accountable for all aspects of the work in ensuring that questions related to the accuracy or integrity of any part of the work are appropriately investigated and resolved.

\section{Competing interests}

None of the sponsors played any role in the study design, the collection, analysis or interpretation of data, the writing of the manuscript or in the decision to submit it for publication. The Collaboration Agreements between FISABIO and Boehringer Ingelheim are a non-conditioned program for conducting independent research in chronic diseases, pharmacoepidemiology and medical practice variation. All authors declare no potential conflicts of interest exist with any companies/ organizations whose products or services may be discussed in this article. Most researchers of the Spanish Atlas of Medical Practice Variation Research Group work in centres or institutions depending on the Health Departments of the Spanish Regional Autonomous Governments. Neither these institutions nor the institutions or firms funding the research project necessarily share the contents of this manuscript.

\section{Consent for publication}

Not applicable.

\section{Ethics approval and consent to participate}

The study, observational in design and with retrospective data irreversibly anonymized prior to their transfer to the research team, was conducted in accordance with the amended Helsinki Declaration, the International Guidelines for Ethical Review of Epidemiological Studies, and Spanish laws on data protection and patients' rights. Due to the nature of the study consent to participate was deemed unnecessary by the ethics committee. The study protocol was approved by the Ethics Committee for Clinical Research of the General Directorate of Public Health and the Centre for Public Health Research (session on March 20, 2014).

\section{Author details}

${ }^{1}$ Centro Superior de Investigación en Salud Pública (CSISP-FISABIO), Catalunya Av. 21, 46020 Valencia, Spain. ${ }^{2}$ Red de Investigación en Servicios de Salud en Enfermedades Crónicas (REDISSEC), Valencia, Spain. ${ }^{3}$ NavarraBiomed - Fundación Miguel Servet, Pamplona, Spain. ${ }^{4}$ Instituto Aragonés de Ciencias de la Salud. IIS Aragón, Zaragoza, Spain.
Received: 11 October 2015 Accepted: 3 August 2016 Published online: 09 August 2016

\section{References}

1. Billings J, Zeitel L, Lukomnik J, Carey TS, Blank AE, Newman L. Impact of socioeconomic status on hospital use in New York City. Health Aff (Millwood). 1993;12(1):162-73.

2. Agency for Healthcare Research and Quality. Guide to Prevention Quality Indicators: hospital admission for ambulatory care sensitive conditions (Version 3.1). Agency for Healthcare Research and Quality; 2007. Available at: http://www.qualityindicators.ahrq.gov/Downloads/Modules/PQI/N31/pqi_ guide_v31.pdf. Accessed 12 Feb 2015.

3. Magán P, Alberquilla A, Otero A, Ribera JM. Hospitalizations for ambulatory care sensitive conditions and quality of primary care: their relation with socioeconomic and health care variables in the Madrid regional health service (Spain). Med Care. 2011;49(1):17-23.

4. Ibañez-Beroiz B, Librero J, Bernal-Delgado E, García-Armesto S, VillanuevaFerragud S, Peiró S. Joint spatial modeling to identify shared patterns among chronic related potentially preventable hospitalizations. BMC Med Res Methodol. 2014;14:74.

5. Thygesen LC, Christiansen T, Garcia-Armesto S, Angulo-Pueyo E, MartínezLizaga N, Bernal-Delgado E, ECHO Consortium. Potentially avoidable hospitalizations in five European countries in 2009 and time trends from 2002 to 2009 based on administrative data. Eur J Public Health. 2015;25 Suppl 1:35-43.

6. Lopez-Campos JL, Ruiz-Ramos M, Soriano JB. Mortality trends in chronic obstructive pulmonary disease in Europe, 1994-2010: a joinpoint regression analysis. Lancet Respir Med. 2014;2(1):54-62.

7. Ford ES. Trends in mortality from chronic obstructive pulmonary disease among adults in the United States. Chest. 2015;148(4):962-70.

8. GBD 2013 Mortality and Causes of Death Collaborators. Global, regional, and national age-sex specific all-cause and cause-specific mortality for 240 causes of death, 1990-2013: a systematic analysis for the Global Burden of Disease Study 2013. Lancet. 2015;385(9963):117-71.

9. Wennberg J, Gittelsohn A. Small area variations in health care delivery. Science. 1973;182:1102-8.

10. Committee on Geographic Variation in Health Care Spending and Promotion of High-Value Care; Board on Health Care Services; Institute of Medicine, Newhouse JP, Garber AM, Graham RP, et al., editors. Variation in Health Care Spending: Target Decision Making, Not Geography. Washington (DC): National Academies Press (US); 2013. Available from: http://www.ncbi. nlm.nih.gov/books/NBK201647/pdf/Bookshelf_NBK201647.pdf. Accessed 12 Feb 2015.

11. Morris RD, Munasinghe RL. Geographic variability in hospital admission rates for respiratory disease among the elderly in the United States. Chest. 1994;106(4):1172-81.

12. O'Malley AS, Pham HH, Schrag D, Wu B, Bach PB. Potentially avoidable hospitalizations for COPD and pneumonia: the role of physician and practice characteristics. Med Care. 2007;45(6):562-70.

13. Holt JB, Zhang X, Presley-Cantrell L, Croft JB. Geographic disparities in chronic obstructive pulmonary disease (COPD) hospitalization among Medicare beneficiaries in the United States. Int J Chron Obstruct Pulmon Dis. 2011;6:321-8.

14. Halvorsen T, Martinussen PE. The geography of chronic obstructive pulmonary disease: a population-based study of Norway. Soc Sci Med. 2014;111:25-34.

15. Farah C, Hosgood 3rd HD, Hock JM. Spatial prevalence and associations among respiratory diseases in Maine. Spat Spatiotemporal Epidemiol. 2014;11:11-22.

16. Martin-Moreno JM, Alonso P, Claveria A, Gorgojo L, Peiró S. Spain: a decentralised health system in constant flux. BMJ. 2009;338:b1170

17. García-Armesto S, Abadía-Taira MB, Durán A, Hernández-Quevedo C, BernalDelgado E. Spain: Health system review. Health Syst Transition. 2010;12(4):1295. Available at: http://www.euro.who.int/_data/assets/pdf_file/0004/ 128830/e94549.pdf. Accessed 1 Aug 2013.

18. Validación de indicadores de calidad utilizados en el contexto internacional: indicadores de seguridad de pacientes e indicadores de hospitalización evitable. Madrid: Ministerio de Sanidad y Consumo; 2008. Available at: http://www.msssi.gob.es/organizacion/sns/planCalidadSNS/docs/Validacion_ indicadores_calidad.pdf. Accessed 1 June 2015. 
19. Bernal-Delgado E, Peiró Moreno S, Dir. Quality of ambulatory care in the Spanish National Health System: analysis of three OECD indicators and some alternatives. Madrid: Ministry of Health and Consumer Affairs; 2009 Available at: http://www.msssi.gob.es/organizacion/sns/planCalidadSNS/ docs/PQI_Spain_WP_2009.pdf. Accessed 1 June 2015

20. Abadía-Taira MB, Martínez-Lizaga N, García-Armesto S, Ridao-López M, Yañez F, Seral-Rodríguez $M$, et al. Variabilidad en las Hospitalizaciones Potencialmente Evitables relacionadas con la reagudización de enfermedades crónicas. Atlas Var Pract Med Sist Nac Salud. 2011;4(2):345-63. Available at: http://www.atlasvpm.org/es/atlas-visor/-/journal_content/56_ INSTANCE_Q9pH/10157/31181. Accessed 1 June 2015.

21. Martínez-Lizaga N, Montes Y, Rodrigo I, Abadía-Taira MB, Ibañez-Beroiz B, Librero-López L, et al. Metodología del Atlas de variaciones en Hospitalizaciones Potencialmente Evitables en el Sistema Nacional de Salud. Atlas Var Pract Med Sist Nac Salud. 2011;4(2):371-8. Available at: http://www.atlasvpm.org/documents/10157/27363/notasmetodologi casatlas8_\%28176KB\%29.pdf. Accessed 1 June 2015.

22. Besag J, York J, Mollie A. Bayesian image restoration, with two applications in spatial statistics. Ann Inst Statist Math. 1991:43:1-59.

23. Knorr-Held L. Bayesian modelling of inseparable space-time variation in disease risk. Stat Med. 2000;19(17-18):2555-67.

24. Richardson S, Thomson A, Best N, Elliott P. Interpreting posterior relative risk estimates in disease-mapping studies. Environ Health Perspect. 2004;112(9):1016-25.

25. Rue H, Martino S, Chopin N. Approximate Bayesian inference for latent Gaussian models using integrated nested Laplace approximations (with discussion). J R Stat Soc Ser B. 2009;71:319-92.

26. R Development Core Team. R: A language and environment for statistical computing. Vienna: R Foundation for Statistical Computing; 2010.

27. de Miguel-Díez J, Jiménez-García R, Hernández-Barrera V, Puente-Maestu L, Rodríguez-Rodríguez P, López de Andrés A, et al. Trends in hospital admissions for acute exacerbation of COPD in Spain from 2006 to 2010. Respir Med. 2013;107(5):717-23.

28. Ford ES. Hospital discharges, readmissions, and emergency department visits for chronic obstructive pulmonary disease or bronchiectasis among US adults: findings from the Nationwide Inpatient Sample 2001-2012 and Nationwide Emergency Department Sample 2006-2011. Chest. 2014. doi:10.1378/chest.14-2146. [Epub ahead of print]

29. Fuhrman C, Roche N, Vergnenègre A, Zureik M, Chouaid C, Delmas MC. Hospital admissions related to acute exacerbations of chronic obstructive pulmonary disease in France, 1998-2007. Respir Med. 2011;105(4):595-601.

30. Benseñor IM, Fernandes TG, Lotufo PA. Chronic obstructive pulmonary disease in Brazil: mortality and hospitalization trends and rates, 1996-2008. Int J Tuberc Lung Dis. 2011;15(3):399-404.

31. Kinnula VL, Vasankari T, Kontula E, Sovijarvi A, Saynajakangas O, Pietinalho A. The 10-year COPD Programme in Finland: effects on quality of diagnosis, smoking, prevalence, hospital admissions and mortality. Prim Care Respir J. 2011;20(2):178-83.

32. Wilson DH, Tucker G, Frith P, Appleton S, Ruffin RE, Adams RJ. Trends in hospital admissions and mortality from asthma and chronic obstructive pulmonary disease in Australia, 1993-2003. Med J Aust. 2007;186(8):408-11.

33. Jeppesen E, Brurberg KG, Vist GE, Wedzicha JA, Wright JJ, Greenstone M, et al. Hospital at home for acute exacerbations of chronic obstructive pulmonary disease. Cochrane Database Syst Rev. 2012;5:CD003573.

34. Kruis AL, Smidt N, Assendelft WJ, Gussekloo J, Boland MR, Rutten-van Mölken $\mathrm{M}$, et al. Integrated disease management interventions for patients with chronic obstructive pulmonary disease. Cochrane Database Syst Rev. 2013;10:CD009437.

35. Instituto Nacional de Estadística. Encuesta de Morbilidad Hospitalaria. Avalaible at: http://www.ine.es/dyngs/INEbase/es/operacion.htm?c=Estadistica_ C\&cid $=1254736176778 \&$ menu=ultiDatos\&idp=1254735573175. Accessed 9 Mar 2016

36. Peköz EA, Shwartz M, lezzoni LI, Ash AS, Posner MA, Restuccia JD. Comparing the importance of disease rate versus practice style variations in explaining differences in small area hospitalization rates for two respiratory conditions. Stat Med. 2003;22(10):1775-86.

37. Shwartz M, Peköz EA, Ash AS, Posner MA, Restuccia JD, lezzoni LI. Do variations in disease prevalence limit the usefulness of population-based hospitalization rates for studying variations in hospital admissions? Med Care. 2005:43:4-11.
38. OECD. Geographic Variations in Health Care. What Do We Know and What Can Be Done to Improve Health System Performance?. OECD Publishing, 2014, Available at: http://www.oecd-ilibrary.org/social-issues-migrationhealth/geographic-variations-in-health-care_9789264216594-en. Accessed 1 Dec 2014.

39. Statistics Canada, Health Information and Research Division: Hospitalizations for ambulatory care sensitive conditions (ACSC) the factors that matter. Ottawa: Statistics Canada, Health Information and Research Division; 2011. Available at: http://epe.lac-bac.gc.ca/100/200/301/statcan/health_research_ working_papers-e/07/82-622-x2011007-eng.pdf. Accessed 25 July 2013.

40. Department of Health. Victorian health information surveillance system (VHISS) - ambulatory care sensitive conditions (ACSCS). Melbourne: State Government of Victoria; 2012. Available at: https://hns.dhs.vic.gov.au/ 3netapps/vhisspublicsite/ViewContent.aspx?TopicID=1\&SubTopicID=10. Accessed 1 June 2015.

41. Davies S, McDonald KM, Schmidt E, Schultz E, Geppert J, Romano PS. Expanding the uses of AHRQ's prevention quality indicators: validity from the clinician perspective. Med Care. 2011;49(8):679-85.

42. Hussey PS, Mattke S, Morse L, Ridgely MS. Evaluation of the use of AHRQ and other quality indicators (AHRQ Publication No. 08-M012-EF). Rockville: Agency for Healthcare Research and Quality; 2007. Available at: http://www.ahrq.gov/research/findings/final-reports/qualityindicators/ qualityindicators.pdf. Accessed 1 June 2015.

43. Peiro S, Bernal Delgado E. Avoidable hospitalizations. Who bears the burden of proof? Rev Calidad Asistencial. 2006;21:173-5.

\section{Submit your next manuscript to BioMed Central and we will help you at every step:}

- We accept pre-submission inquiries

- Our selector tool helps you to find the most relevant journal

- We provide round the clock customer support

- Convenient online submission

- Thorough peer review

- Inclusion in PubMed and all major indexing services

- Maximum visibility for your research

Submit your manuscript at www.biomedcentral.com/submit
BioMed Central 